\title{
AVALIAÇÃO DE RISCO TOXICOLÓGICO PARA HIDROCARBONETOS TOTAIS DE PETRÓLEO EM FORMA FRACIONADA APLICADA À GESTÃO E MONITORAMENTO DE ÁGUA SUBTERRÂNEA EM UM COMPLEXO INDUSTRIAL
}

\author{
Celso Kolesnikovas ${ }^{1}$, Everton de Oliveira $^{1,2}$ e Uriel Duarte ${ }^{3}$
}

\begin{abstract}
RESUMO:
Este estudo examinou o risco toxicológico associado à presença de hidrocarbonetos totais de petróleo dispostos no meio ambiente, verificando a influência de se considerar toda a gama de hidrocarbonetos de petróleo na avaliação de risco, em comparação com a avaliação de risco clássica, onde apenas são considerados os compostos padronizados, Benzeno, Tolueno, Etilbenzeno e Xilenos (BTEX).

As simulações de risco efetuadas somente para os compostos BTEX indicaram valores acima dos limites preconizados pelos órgãos ambientais somente em um cenário hipotético de utilização de água captada em área próxima ao poço de monitoramento denominado PPTX 070. Os demais cenários apresentam riscos dentro dos limites aceitáveis.

A quantificação do risco toxicológico associado a toda a gama de hidrocarbonetos de petróleo apresentou valores mais restritivos do que as avaliações executadas para a mesma amostra quando considerou-se somente os compostos padronizados (BTEX). As variações foram de até duas ordens de grandeza no quociente de risco.

Assim, a definição de metas de remediação e adoção de um programa de gestão específico deve considerar toda a gama de hidrocarbonetos de petróleo e não somente compostos padronizados.
\end{abstract}

ABSTRACT: $\quad$ This study examined the toxicological risk associated with the petroleum hydrocarbon disposal in the environment, and verified the influence of considering the total petroleum hydrocarbon range in the risk evaluation, in comparison with the classical risk evaluation which solely consider the compounds, Benzene, Toluene, Etilbenzene and Xylene (BTEX).

The risk simulations performed for the BTEX compounds indicated values above the limits accepted by the environmental agencies only for a hypothetical scenery regarding exploitation of water nearby the PPTX 070 well area. The other sceneries presented acceptable risk limits.

The toxicological risk associated to the total petroleum hydrocarbon range presented more restrictive values than the evaluations performed for the same water sample, when it was considered only the standardized compounds (BTEX). The variations went up to two orders of magnitude in the risk quotient.

Thus, the definition of remediation goals and adoption of a specific management program must consider the total petroleum hydrocarbon range and not only the standardized compounds (BTEX).

\section{CONHECIMENTO DO PROBLEMA}

\section{A Avaliação de Risco}

O conceito fundamental de avaliação de risco (ASTM, 1995; 2000) está baseado em três componentes essenciais: contaminantes perigosos, vetores de exposição e receptores, os quais devem estar presentes para que se aplique a metodologia de avaliação de risco.

A metodologia baseia-se na execução de três fases principais, a formulação do problema, a análise e a caracterização do risco.

$\mathrm{Na}$ formulação do problema devem ser definidos os três principais componentes do risco à saúde humana: compostos químicos, vetores (rotas) de exposição e receptores; seguindo-se o levantamento e análise de dados relativos às características do empreendimento e a sua área de influência, incluindo as etapas do processo operacional, as cargas de contaminantes liberadas, sua dispersão no sistema ambiental e a descrição dos meios físicos e bióticos.

$\mathrm{Na}$ fase analítica, devem ser identificados os componentes químicos relevantes para a avaliação de riscos e os fatores ecológicos preponderantes a serem considerados neste processo. A seleção desses compostos é baseada em propriedades toxicológicas (capacidade inerente de um agente causar efeitos adversos em um organismo vivo). e físico-químicas, periculosidade da substância, propriedades de particionamento do composto e/ou elemento, mobilidade; concentrações do composto no meio e vias de exposição.

O modelo conceitual resultante vai associar o risco que um ou mais contaminantes possam causar a um receptor potencial, de acordo com o comportamento destes contaminantes no meio ambiente.

A análise da exposição e da toxicidade envolve a estimativa da assimilação diária, pelo receptor, de compostos químicos associados ao local contaminado, via ingestão, inalação ou absorção cutânea (USEPA,1992). A assimilação diária total de um composto químico específico é a somatória das assimilações diárias para cada vetor de interesse identificado na formulação do problema.

\footnotetext{
${ }^{1}$ Hidroplan Ltda

${ }^{2} I G C E$-Unesp

${ }^{3} I G c-U S P$
} 
através de ingestão, inalação e contato dermal,fator usado posteriormente na caracterização do risco.

A avaliação da toxicidade envolve a identificação dos efeitos tóxicos potenciais dos compostos e a estimativa da dosagem máxima para cada composto que não causa efeitos adversos mensuráveis para os receptores em questão (dose de segurança). A dose de referência é estimada para as três formas de assimilação: ingestão, inalação e contato cutâneo e, usada posteriormente para se obter, matematicamente, em conjunto com a assimilação diária total, uma estimativa de risco.

A caracterização do risco envolve a quantificação dos riscos aos receptores potenciais que estejam expostos a todos os compostos químicos de interesse e as rotas de exposição identificados na formulação do problema, e que apresentem os maiores potenciais para contribuir com riscos mensuráveis aos receptores sensíveis. As estimativas de risco envolvem o cálculo de três parâmetros definidos pela USEPA (1986b): a "Dose Diária Média de Ingresso - DDI", a "Dose de Referência - DfR", e o "Fator de Potência FP"; os quais permitem o cálculo dos parâmetros, o "Incremento de Risco - IR" e o "Quociente de Risco - QR".

O Incremento de Risco - (IR) é definido para compostos carcinogênicos (USEPA, 1986b), e representa o risco produzido pela exposição diária durante toda a vida a um $\mathrm{mgK}^{-1} \mathrm{dia}^{-1}$ do composto. O IR é dado pela Dose Diária Média de Ingresso (DDI, derivado de Average Daily Dose - ADD) multiplicado pelo Fator de Potência (FP, derivado da sigla de Slope Factor - SF), característico de cada composto, que é a tangente da curva doseresposta. Quanto mais inclinada a curva, maior a probabilidade de se desenvolver a doença devido à exposição e conseqüente dose desse composto.

$$
\mathrm{IR}=\mathrm{DDI} \times \mathrm{FP}
$$

O Quociente de Risco (QR, derivado de HQ sigla de Hazard Quotient) é baseado na Dose de Referência (RfD), que é a estimativa da exposição diária $\left(\mathrm{mgK}^{-1} \mathrm{dia}^{-1}\right)$ para a qual uma população humana não está sujeita a nenhum efeito adverso, durante uma vida inteira de exposição; e na Dose de Ingresso Diária Média -DDI pelo receptor. Caso o DDI seja maior que o RfD, o quociente de risco é positivo.

$$
\mathrm{QR}=\frac{D D I}{R f D}
$$

A Dose Diária Média de Ingresso (DDI) é a relação entre a concentração do composto de interesse no ponto de exposição, através de uma taxa de ingresso, freqüência e duração da exposição e peso corpóreo. A DDI é a dose crônica que é utilizada quando o período de exposição coincide com o tempo de vida. Contudo, para o cálculo do risco carcinogênico, é comum que o período de exposição do receptor a determinado contaminante seja diferente de sua expectativa de vida. O LADD (Life-Time Average Daily Dose) é definido como o ingresso médio diário integral, ou seja, é a média da quantidade de todo contaminante a que o receptor está sujeito pela sua expectativa de vida.

Sendo a Dose de Referência (RfD) um parâmetro advindo de concentrações em que não são observáveis efeitos adversos à saúde, denominada NOAEL (Non Observed Adverse Effect Level), adicionado de um fator de incerteza de pelo menos uma ordem de grandeza, em função de confiabilidade estatística, evidências menores que o tempo de avaliação de uma vida e ainda extrapolação para seres humanos de dados obtidos em ensaios com animais, fica claro o conservadorismo dos estudos baseados em risco, conforme definição da USEPA.

\section{Hidrocarbonetos de Petróleo: Características Importantes na Avaliação de Risco Toxicológico}

O petróleo é uma mistura de hidrocarbonetos formados por átomos de carbono e hidrogênio, além de pequenas quantidades de enxofre, nitrogênio e oxigênio em proporções variáveis. A composição percentual aproximada dos diversos elementos químicos encontra-se na Tabela 1.

Tabela 1: Composição do Petróleo

\begin{tabular}{|c|c|}
\hline Elemento & $\begin{array}{c}\text { Concentração } \\
\text { Percentual \% }\end{array}$ \\
\hline Carbono & 81 a 88 \\
\hline Hidrogênio & 10 a 14 \\
\hline Oxigênio & 0,001 a 1,2 \\
\hline Nitrogênio & 0,002 a 1,7 \\
\hline Enxofre & 0,01 a 5 \\
\hline
\end{tabular}


Os hidrocarbonetos de petróleo podem ser agrupados em quatro classes principais, baseadas na composição molecular: aromáticos, alcanos, alcenos e cicloalcanos (API 1999).

Aromáticos: São hidrocarbonetos de cadeia benzênica que estão presentes em praticamente todos os tipos de petróleo, embora em pequenas quantidades na maioria deles. São os que apresentam maior toxicidade e biodegradação lenta e estão associados a efeitos crônicos e carcinogênicos. Os hidrocarbonetos com dois ou mais anéis aromáticos são denominados de Hidrocarbonetos Policíclicos Aromáticos (HPA), também classificados como Poluentes Orgânicos Persistentes (POP). Constituem os principais produtos da combustão incompleta da matéria orgânica, sendo potencialmente perigosos e amplamente distribuídos pelo meio ambiente na forma de misturas complexas.

Alcanos (parafinas ou alifáticos saturados): hidrocarbonetos de cadeias normais e ramificadas. Compreendem a maior fração da maioria dos petróleos. São incolores, relativamente inodoros e pouco reativos. A toxicidade geralmente é baixa e são facilmente biodegradados.

Alcenos (olefinas): hidrocarbonetos de cadeia aberta, similar aos alcanos diferindo apenas pela presença de ligação dupla entre os átomos de carbono. Geralmente estão ausentes ou aparecem em pequenas quantidades no petróleo, mas são abundantes em produtos de refino como a gasolina.

Cicloalcanos (naftas): hidrocarbonetos de cadeias fechadas (cíclicas) e saturadas. Compreendem a segunda maior fração da maioria dos petróleos.

A gasolina, líquido composto por uma mistura de hidrocarbonetos de petróleo, é comumente representada em avaliações ambientais pelos hidrocarbonetos aromáticos benzeno, tolueno, etilbenzeno e xilenos, conjuntamente denominados BTEX, que representam em torno de $20 \%$ em massa (API 1985) e são característicos da faixa C6 a C8 (número de carbonos equivalentes).

O óleo diesel apresenta analogia semelhante, com relação aos hidrocarbonetos policíclicos aromáticos, sendo considerados como principais componentes os compostos: antraceno, benzo(a) pireno, benzo(a)antraceno, benzo(b)fluoranteno, benzo(g,h,i)perileno, benzo(K)fluoranteno, indeno(1,2,3)pireno, criseno, fenantreno, fluoranteno, fluoreno e naftaleno.

FRONAPE (2002) classifica o Petróleo e seus derivados em função de suas propriedades, conforme ilustrado na Tabela 2:

Tabela 2: Classificação do Petróleo em função de suas propriedades

\begin{tabular}{|c|c|}
\hline Tipo & Principais Propriedades \\
\hline $\begin{array}{l}\text { TIPO I - Produtos refinados muito leves } \\
\qquad \begin{array}{c}\text { Gasolina } \\
\text { Nafta } \\
\text { Solventes } \\
\text { Gasolina de aviação } 80 / 100\end{array}\end{array}$ & $\begin{array}{l}\text { - Muito volátil e altamente inflamável } \\
\text { - Elevadas taxas de evaporação } \\
\text { • Baixa viscosidade } \\
\text { • Peso específico menor que } 0,80 \\
\text {-Toxicidade aguda elevada para a biota }\end{array}$ \\
\hline $\begin{array}{c}\text { TIPO II - Produtos semelhantes ao diesel e petróleos brutos } \\
\text { leves } \\
\text { Óleo combustível } \\
\text { Querosene (QAV) } \\
\text { Combustível marítimo } \\
\text { Petróleo bruto "West Texas" } \\
\text { Petróleo bruto "Alberta" }\end{array}$ & $\begin{array}{c}\text { • Moderadamente volátil } \\
\text { • Evaporação das frações leves } \\
\text { • Peso específico de } 0,80-0,85 \\
\text { • Toxicidade aguda moderada a elevada para a biota; } \\
\text { toxicidade específica do produto diretamente relacionada } \\
\text { com o tipo e concentração dos compostos aromáticos na } \\
\text { fração solúvel na água }\end{array}$ \\
\hline $\begin{array}{l}\text { TIPO III - Hidrocarbonetos médios e produtos intermediários } \\
\text { Petróleo bruto "North Slop" } \\
\text { Petróleo bruto "South Louisiana" } \\
\text { Óleos combustíveis } \\
\text { intermediários } \\
\text { Óleo de lubrificação }\end{array}$ & $\begin{array}{c}\text { • Moderadamente volátil } \\
\text { • Evaporação até } 1 / 3 \text { do volume derramado } \\
\bullet \text { Viscosidade moderada a elevada } \\
\text { • Peso específico de } 0,85-0,95 \\
\text { - Toxicidade aguda variável para a biota dependendo da } \\
\text { quantidade da fração leve } \\
\text { • Podem formar emulsões estáveis }\end{array}$ \\
\hline $\begin{array}{l}\text { TIPO IV - Petróleos brutos pesados e produtos residuais } \\
\text { Petróleo bruto "Venezuela" } \\
\text { Petróleo bruto "San JoaquinValley", } \\
\text { Bunker C } \\
\text { Óleo combustível no } 6\end{array}$ & $\begin{array}{c}\text { • Ligeiramente volátil } \\
\text { - Evaporação de uma pequena parcela do volume derra- } \\
\text { mado } \\
\text { - Muito viscosos a semi-sólidos; podem tornar-se menos } \\
\text { viscosos quando aquecidos pela luz solar } \\
\text { • Peso específico de } 0,95-1,00 \\
\text { - Baixa toxicidade aguda relativamente aos outros tipos } \\
\text { de hidrocarbonetos } \\
\text { • Formam emulsões estáveis }\end{array}$ \\
\hline
\end{tabular}


A persistência no meio ambiente, fator baseado no tempo em que um produto permanece em determinado meio é extremamente importante na avaliação de risco toxicológico, uma vez que a taxa de ingresso de contaminantes é função também do tempo de exposição do receptor ao contaminante. A persistência também é definida como a quantidade do produto original que permanece no solo, sedimento, e coluna d' água após um derrame. Dentre os hidrocarbonetos de petróleo são classificados como não persistentes os produtos refinados de petróleo, cuja composição apresenta maior percentual de componentes de peso leve, que tendem a evaporar e dissipar rápida e naturalmente e que raramente requerem limpeza (ITOPF, 2001). São considerados persistentes aqueles petróleos e produtos refinados, constituídos por uma mistura de componentes de peso leve e intermediário e componentes pesados que tendem a se dissipar mais vagarosamente (CETESB, 2004). Uma vez expostos ao meio ambiente, a composição dos produtos vai sofrendo modificações à medida que os componentes vão sendo evaporados ou removidos pelos processos de intemperismo.

A Tabela 3 apresenta as cinco categorias de persistência relativa dos óleos e derivados do petróleo, API (1999).

Tabela 3: Caracterização do petróleo em função da persistência no ambiente

\begin{tabular}{|c|c|c|}
\hline Categoria & Persistência & Exemplos \\
\hline Grupo I & Não persistente & gasolina \\
\hline Grupo II & Persistente & Diesel, óleo cru leve \\
\hline Grupo III & Persistente & Óleo cru intermediário \\
\hline Grupo IV & Persistente & óleo cru pesado, residual \\
\hline Grupo V & persistente & Produtos com baixo grau API \\
\hline
\end{tabular}

No tocante à avaliação de risco, a modificação do produto no meio ambiente e conseqüente perda de características originais alteram as relações de exposição e toxicidade dos mesmos.

\section{Utilização de Frações de Hidrocarbonetos Totais de Petróleo (TPH) na Avaliação de Risco Toxicológico}

O parâmetro TPH tem sido aceito pelas agências reguladoras ambientais para avaliação dos processos de monitoramento e remediação, bem como para critérios de remediação de solos impactados por óleo diesel (DOUGLAS et al., 1994; HUESEMANN \& MOORE, 1994; NORRIS et al., 1994; PRINCE et al., 1994; TROY \& JERGER, 1994). Entretanto, a norma ASTM E 1739/95, a base de todos os estudos relativos às avaliações de risco, desaconselha a utilização de parâmetros genéricos, como o TPH (hidrocarbonetos totais de petróleo) por não serem consideradas as características físico-químicas e toxicológicas dos constituintes individuais da mistura (item 6.4.3 da norma ASTM E 1739).

Para XIE et al. (1999) de fato, os TPH, dado pela soma dos hidrocarbonetos aromáticos e alifáticos de petróleo, não devem ser inseridos nas ARA por não terem seus parâmetros toxicológicos definidos.

Discordando desse pensamento, Vorhees (1999) defende que, a utilização de frações de mistura de hidrocarbonetos (faixas de TPH que possuem número de carbono equivalente definidos) é uma ferramenta bastante atraente por considerar toda a gama de hidrocarbonetos e não somente os compostos: benzeno, tolueno, etilbenzeno e xilenos entre os aromáticos; e antraceno, benzo(a)pireno, benzo(a)antraceno, benzo(b)fluoranteno, benzo(g,h,i)perileno, benzo(K)fluoranteno, indeno(1,2,3)pireno, criseno, fenantreno, fluoranteno, fluoreno e naftaleno entre os poliaromáticos (Vorhees1999).

No trabalho desse autor, a metodologia utilizada para a avaliação de toxicidade levou em conta dois importantes mecanismos de transporte, solubilização para aágua subterrânea e volatilização para o ar. Foram agrupados os compostos individuais com as mesmas características, perante os mecanismos de transporte acima citados, objetivando a determinação das frações. Os fatores de volatilização e de solubilização foram plotados para faixas de números de carbono equivalentes (CE) para cada composto. Isso mostra que compostos alifáticos e aromáticos apresentam características distintas no meio ambiente. Os aromáticos tendem a ser mais solúveis em água e pouco menos voláteis do que os alifáticos de número de carbono equivalente (CE). Dividindose a faixa total de hidrocarbonetos nesses dois grupos principais, verifica-se que os fatores de volatilização e solubilização variam em ordens 
de magnitude. Uma vez subdivididos, à cada nova fração foram atribuídos os coeficientes de particionamento (transporte ambiental) baseado na correlação com seu número de carbono equivalente (CE); e, através dessa correlação foi possível estabelecer os fatores de exposição humana para misturas complexas de hidrocarbonetos petróleo.

Nessa metodologia, a toxicidade da fração não muda de acordo com fontes diversas do produto de petróleo, ou seja, a toxicidade da faixa alifática CE-10 a CE-12 de um derramamento de gasolina, corresponde à mesma faixa alifática de CE de um óleo combustível tipo \#2. Esta metodologia foi corroborada pela Texas Risk Reduction Program Draft Guidance for Development of PCL's for TPH Mixtures (TRRP 2000), definindo-a como Norma.

Nessa mesma linha de pensamento, o trabalho de Verbrugen (2004) definiu limites ambientais do risco para o óleo mineral (hidrocarbonetos totais do petróleo). O método desse autor é baseado em uma aproximação da toxicidade de cada fração, em que os compostos alifáticos e aromáticos são considerados separadamente.

Outra definição para os hidrocarbonetos totais de petróleo é dada pelo Departamento de Qualidade ambiental de Oklahoma (DEQ), EUA, como a faixa de carbono variando entre C6 e $\mathrm{C} 35$, representando a variada e complexa mistura de compostos. São definidas ainda três faixas de TPH: faixas de gasolina (C6- C12), faixa de diesel (C12-C22) e faixa de óleo lubrificante (C22-C35); todas passíveis de determinação de metas de remediação baseadas em risco (OKLAHOMA DEQ, 2004).. Para cada uma dessas faixas, foram determinadas as metas de remedição, baseadas em risco, de acordo com os três níveis (denominados tier) prescritos na norma ASTM-1739/85 (RBCA). Nessa metodologia não foram consideradas as propriedades de comportamento e toxicológicas das faixas alifáticas e aromáticas, de mesmo número de carbono equivalente.

\section{APLICAÇÃO DA METODOLOGIA DE ANÁLISE DE RISCO}

\section{Avaliação de risco para hidrocarbonetos padronizados (BTEX)}

\section{- Área de Estudo e Caracterização dos Cenários}

A área estudada foi o Pólo Petroquímico de Triunfo. As empresas Petroflex e Oxiteno pertencentes ao Pólo Petroquímico Sul foram consideradas como áreas potenciais de enfoque, devido às mesmas apresentarem as máximas concentrações de Benzeno, Etilbenzeno, Tolueno e Xilenos totais (BTEX) nos eventos de monitoramento analítico da água subterrânea efetuados em toda área do pólo petroquímico no período de 1999 a 2005. Essas áreas apresentaram valores de compostos remanescentes de TPH e foram objeto de avaliação de risco.

$\mathrm{O}$ estudo contemplou a caracterização dos cenários reais, bem como dos cenários conservativos (potenciais), objetivando a verificação dos riscos em função de futuras alterações do uso da área estudada.

Como pressuposto, foi considerado que as máximas concentrações dos compostos de interesse na água subterrânea, identificadas nos poços de monitoramento P-PTX-070 (Petroflex) e P-OXI-029 (Oxiteno), poderiam atingir o Rio Caí, existente a 800 e 2.500 metros, respectivamente, a jusante desses poços, bem como a população residencial e comercial existente no entorno que viessem a ter contato com a água do rio. Entretanto, os resultados da simulação de transporte de solutos, indicaram que os compostos de interesse detectados na água subterrânea, nas amostras coletadas nos poços de monitoramento, não alçariam uma distância superior a 80 metros, ou seja, não ultrapassariam os limites da área do pólo petroquímico em tempo infinito.

Foi considerado como cenário potencial, a instalação de um poço de captação de água subterrânea na empresa Petroflex, próximo ao poço de monitoramento P-PTX-070, o qual apresentou as maiores concentrações dos compostos: Benzeno, Etilbenzeno e Xilenos totais; bem como a instalação de um poço de captação de água subterrânea na empresa Oxiteno, próximo ao poço de monitoramento P-OXI-029, o qual apresentou a maior concentração de Tolueno.

\section{- Caracterização das rotas de exposição, receptores e cenários}

Para a área em estudo, os cenários reais para avaliação dos risco compreenderam as rotas advindas de inalação de vapores provenientes da água subterrânea em ambientes fechados e abertos pelos funcionários das empresas Petroflex e Oxiteno, pertencentes ao Pólo Petroquímico Sul. Os cenários reais ficaram assim distribuídos: $\mathrm{Na}$ Petroflex ficaram localizados os cenários 1 e 3, sendo 1 o ambiente aberto, e 3 o ambiente fechado; e na Oxiteno, ficaram os cenários reais 2 e 4 , sendo 2 o ambiente aberto, e 4 o ambiente fechado.

Quanto aos cenários potenciais, no cenário 
potencial 1 as rotas de exposição seriam as advindas da ingestão e absorção dérmica através da água do Rio Caí, localizado à jusante da área do Pólo Petroquímico Sul, pelos trabalhadores, crianças e outros residentes do entorno durante uma eventual exposição. No cenário potencial 2, as rotas de exposição seriam a ingestão, inalação de gotículas e vapores durante banho e irrigação, e absorção dérmica da água subterrânea de um eventual poço de captação instalado próximo ao poço de monitoramento P-PTX-070, pelos trabalhadores da Petroflex. Enquanto no cenário potencial 3, o risco seriam devido a condições similares ao cenário 2 , devido a um eventual poço de captação instalado próximo ao poço de monitoramento P-OXI-029, situado na empresa Oxiteno.

\section{- Definição dos Compostos de Interesse}

Para os Cenários Reais 1 e 3 os compostos de interesse (CI) foram selecionados quantitativamente, baseando-se na concentração máxima detectada dos compostos Benzeno, Tolueno, Etilbenzeno e Xilenos totais (BTXE) durante os eventos de monitoramento de água subterrânea realizados na empresa Petroflex no período de 1999 e 2005, conforme apresentado na Tabela 4.

Tabela 4: Concentrações dos compostos de interesse em água subterrânea consideradas para a avaliação de risco (Cenários Reais 1 e 3 e Potencial 2)

\begin{tabular}{|c|c|c|c|c|}
\hline $\begin{array}{l}\text { Composto de } \\
\text { interesse }\end{array}$ & \multirow{4}{*}{ 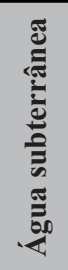 } & $\begin{array}{c}\text { Máxima } \\
\text { concentração } \\
(\mathrm{mg} / \mathrm{L})\end{array}$ & Ponto de coleta & Data de coleta \\
\hline Benzeno & & 1,133 & P-PTX-070 & Set/02 \\
\hline Etilbenzeno & & 17,700 & P-PTX-070 & Mar/02 \\
\hline Xilenos totais & & 1,530 & P-PTX-070 & Out/00 \\
\hline
\end{tabular}

Para os Cenários Reais 2 e 4 e para o Cenário Potencial 3, os compostos de interesse (CI) foram selecionados quantitativamente, baseando-se na concentração máxima detectada de BTEX durante os eventos de monitoramento de água subterrânea realizados na empresa Oxiteno no período de 1999 e 2005, conforme apresentado na Tabela 5.

Tabela 5: Concentrações dos compostos de interesse em água subterrânea consideradas para a avaliação de risco (Cenários Reais 2 e 4 e Potencial 3)

\begin{tabular}{|c|c|c|c|c|}
\hline $\begin{array}{l}\text { Composto de } \\
\text { interesse }\end{array}$ & \multirow{3}{*}{ 学 } & $\begin{array}{c}\text { Máxima concentração } \\
(\mathrm{mg} / \mathrm{L})\end{array}$ & Ponto de coleta & Data de coleta \\
\hline Tolueno & & 0,330 & P-OXI-029 & $\mathrm{Mar} / 00$ \\
\hline Xilenos totais & & 0,022 & P-OXI-029 & $\mathrm{Mar} / 03$ \\
\hline
\end{tabular}

Em relação ao Cenário Potencial 1, os compostos de interesse (CI) foram selecionados quantitativamente, baseando-se na concentração máxima detectada de BTXE durante os eventos de monitoramento de água subterrânea realizados em todas empresas do Pólo Petroquímico Sul no período de 1999 e 2005, conforme apresentado na Tabela 6. 
Tabela 6: Concentrações dos compostos de interesse em água subterrânea consideradas para a avaliação de risco (Cenário Potencial 1)

\begin{tabular}{|c|c|c|c|c|}
\hline $\begin{array}{l}\text { Composto de } \\
\text { interesse }\end{array}$ & \multirow{5}{*}{ 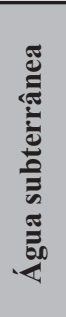 } & $\begin{array}{c}\text { Máxima } \\
\text { concentração } \\
(\mathrm{mg} / \mathrm{L})\end{array}$ & Ponto de coleta & Data de coleta \\
\hline Benzeno & & 1,133 & P-PTX-070 & Set/02 \\
\hline Etilbenzeno & & 17,700 & P-PTX-070 & $\mathrm{Mar} / 02$ \\
\hline Tolueno & & 0,330 & P-OXI-029 & $\mathrm{Mar} / 00$ \\
\hline Xilenos totais & & 0,108 & P-PTX-070 & Out $/ 00$ \\
\hline
\end{tabular}

- Parâmetros de Exposição para os Cenários de Reais 1 e 2, e, 3 e 4, respectivamente, para inalação Interesse de vapores em ambientes abertos e fechados, pelos

A Tabela 7 apresenta os parâmetros de funcionários da Petroflex e Oxiteno. exposição definidos para os pares de Cenários

Tabela 7: Parâmetros de exposição para os Cenários Reais 1, 2, 3 e 4

\begin{tabular}{|c|c|}
\hline \multicolumn{2}{|c|}{ Trabalhador - Exposição Típica } \\
\hline Expectativa de Vida (anos) & 68 \\
\hline Peso Corpóreo (kg) & 60 \\
\hline Frequência de Exposição em Ambiente Aberto (eventos/ano) & 288 \\
\hline Frequência de Exposição em Ambiente Fchado (eventos/ano) & 35 \\
\hline Fator de Retenção no Pulmão (-) & 0.75 \\
\hline Taxa de Inalação em Ambiente Aberto $\left(\mathrm{m}^{3} / \mathrm{h}\right)$ & 0.833 \\
\hline Tempo de Permanência em Ambiente Aberto $(\mathrm{h} / \mathrm{dia})$ & 8 \\
\hline
\end{tabular}

A Tabela 8 apresenta os parâmetros de (Rio Caí) durante a recreação pelos residentes e exposição para o Cenário Potencial 1, ou seja, a trabalhadores do entorno. ingestão e absorção dérmica de água superficial

Tabela 8: Parâmetros de exposição para o Cenário Potencial 1

\begin{tabular}{|c|c|c|}
\hline & $\begin{array}{c}\text { Residente- } \\
\text { Criança }\end{array}$ & $\begin{array}{c}\text { Trabalhador Exposição } \\
\text { Típica }\end{array}$ \\
\hline Expectativa de Vida (anos) & 68 & 68 \\
\hline Peso Corpóreo $(\mathrm{kg})$ & 15 & 60 \\
\hline Frequência de Exposição - natação- (eventos/ano) & 180 & 180 \\
\hline Duração de Exposição - natação - (ano) & 6 & 35 \\
\hline Taxa de Ingestão (ml/h) & 50 & 50 \\
\hline Tempo de Permanência durante a natação (h/dia) & 2 & 1 \\
\hline Área Corpórea Total $\left(\mathrm{cm}^{2}\right)$ & 9500 & 16600 \\
\hline
\end{tabular}

A Tabela 9 ilustra os parâmetros de exposição para os Cenários Potenciais 2 e 3. 
Tabela 9: Parâmetros de exposição para os Cenários Potenciais 2 e 3

\begin{tabular}{|c|c|}
\hline \multicolumn{2}{|l|}{ Trabalhador - Exposição Típica } \\
\hline Expectativa de Vida (anos) & 69 \\
\hline Peso Corpóreo (kg) & 60 \\
\hline Frequência de Exposição à Água Subterrânea (eventos/ano) & 288 \\
\hline Duração da Exposição à Água Subterrânea (ano) & 35 \\
\hline Fator de Retenção no Pulmão (-) & 0,75 \\
\hline Taxa de Ingestão de Água (L/dia) & 1,0 \\
\hline Tempo de Exposição durante o Banho (h/dia) & 0,2 \\
\hline Área corpórea Total $(\mathrm{cm} 2)$ & 16600 \\
\hline Taxa de Inalação durante o Banho (m3/h) & 0,833 \\
\hline Volume do Banheiro (m3) & 6 \\
\hline Vazão do Chuveiro (L/min) & 12,5 \\
\hline Temperatura da Água do Chuveiro $\left({ }^{\circ} \mathrm{C}\right)$ & 39,85 \\
\hline Frequência de Exposição à Água de Irrigação (eventos/ano) & 288 \\
\hline Taxa de Ingestão de Água durante a Irrigação (L/dia) & 0,5 \\
\hline Tempo em Contato com Água de Irrigação (h/dia) & 8 \\
\hline Taxa de Inalação em Ambiente Aberto & 0,833 \\
\hline Vazão do Aspersor (L/min) & 30 \\
\hline Temperatura da Água de Irrigação $\left({ }^{\circ} \mathrm{C}\right)$ & 20 \\
\hline Altura da Zona Respirável (m) & 2 \\
\hline Velocidade Média dos Ventos $(\mathrm{m} / \mathrm{s})$ & 2,25 \\
\hline Fração da Pele Exposta (-) & 0,51 \\
\hline
\end{tabular}

Para o risco não carcinogênico aceitável foi utilizado o fator de risco de 1 estabelecido pela CETESB (2001), que configura uma dose diária média de ingresso (DDI) igual à dose de referência para o composto (DRf).

As simulações de partição dos contaminantes da água subterrânea para $\mathrm{o}$ ar foram realizadas para um período de 35 anos, baseado no tempo de atividade profissional do trabalhador típico brasileiro (CETESB, 2001).

Todos os parâmetros de exposição assumidos para o cenário considerado foram obtidos através do Relatório de Estabelecimento de Valores Orientadores para o Estado de São Paulo, do Procedimento para Ações Corretivas Baseadas em Risco - ACBR (CETESB, 2001) e da versão preliminar do capítulo 9 "Avaliação de risco à saúde humana" do Manual de Gerenciamento de Áreas Contaminadas"(CETESB, 2004), assumindo-se os valores mais restritivos.

\section{RESULTADOS E DISCUSSÃO DA AVALIAÇÃO DE RISCO}

\section{Cálculo do risco considerando-se apenas BTEX}

Os resultados do cálculo do risco efetuados com o programa de suporte RISC $\AA$ versão 4.04 (fabricante, cidade, estado) estão apresentados na Tabela 10. A tabela apresenta um sumário dos incrementos de risco (efeitos carcinogênicos) e quocientes (efeitos não carcinogênicos) calculados para os cenários reais e potenciais escolhidos, e de acordo com as máximas concentrações identificadas para os compostos BTEX. 
Tabela 10: Sumários dos incrementos e quocientes de riscos calculados para os cenários reais BTEX

\begin{tabular}{|c|c|c|c|c|c|c|}
\hline \multicolumn{7}{|c|}{ Com as máximas concentrações (excluindo as concentrações de TPH) } \\
\hline Cenário & Area & Receptores & Fonte & Rotas de Exposição & $\begin{array}{c}\text { Incremento } \\
\text { de Risco }\end{array}$ & $\begin{array}{l}\text { Quociente } \\
\text { de Risco }\end{array}$ \\
\hline \multirow[t]{2}{*}{ Potencial 1} & \multirow[t]{2}{*}{ Rio Caí } & $\begin{array}{c}\text { Residentes } \\
\text { (representados por } \\
\text { uma criança típica) }\end{array}$ & \multirow{2}{*}{$\begin{array}{c}\text { Água } \\
\text { superficial }\end{array}$} & \multirow[t]{2}{*}{$\begin{array}{l}\text { Contato dérmico e } \\
\text { ingestão. }\end{array}$} & $0,00 \mathrm{E}+00$ & $0,00 \mathrm{E}+00$ \\
\hline & & Trabalhadores & & & $0,00 \mathrm{E}+00$ & $0,00 \mathrm{E}+00$ \\
\hline Potencial 2 & Petroflex & Trabalhadores & $\begin{array}{c}\text { Água } \\
\text { subterrânea }\end{array}$ & $\begin{array}{l}\text { Contato dérmico, ingestão } \\
\text { e inalação de vapores e } \\
\text { gotículas. }\end{array}$ & $9,60 \mathrm{E}-04$ & $3,20 \mathrm{E}+01$ \\
\hline Potencial 3 & Oxiteno & Trabalhadores & $\begin{array}{c}\text { Água } \\
\text { subterrânea }\end{array}$ & $\begin{array}{l}\text { Contato dérmico, ingestão } \\
\text { e inalação de vapores e } \\
\text { gotículas. }\end{array}$ & - & $1,80 \mathrm{E}-01$ \\
\hline Real 1 & Petroflex & Trabalhadores & $\begin{array}{c}\text { Água } \\
\text { subterrânea }\end{array}$ & $\begin{array}{l}\text { Inalação de vapores em } \\
\text { ambientes abertos }\end{array}$ & $1,60 \mathrm{E}-08$ & $2,50 \mathrm{E}-04$ \\
\hline Real 2 & Oxiteno & Trabalhadores & $\begin{array}{c}\text { Água } \\
\text { subterrânea }\end{array}$ & $\begin{array}{l}\text { Inalação de vapores em } \\
\text { ambientes abertos }\end{array}$ & - & 4,00E-06 \\
\hline Real 3 & Petroflex & Trabalhadores & $\begin{array}{c}\text { Água } \\
\text { subterrânea }\end{array}$ & $\begin{array}{l}\text { Inalação de vapores em } \\
\text { ambientes fechados }\end{array}$ & $1,20 \mathrm{E}-06$ & 1,90E-02 \\
\hline Real 4 & Oxiteno & Trabalhadores & $\begin{array}{c}\text { Água } \\
\text { subterrânea }\end{array}$ & $\begin{array}{l}\text { Inalação de vapores em } \\
\text { ambientes fechados }\end{array}$ & - & $3,10 \mathrm{E}-04$ \\
\hline
\end{tabular}

Observa-se na Tabela 10 que, para os cenários reais nesta avaliação de risco, não foram obtidos incrementos e quocientes de riscos superiores aos limites preconizados pela CETESB (2001) para compostos carcinogênicos $\left(10^{-5}\right)$ e não carcinogênicos $(1,0)$. No entanto, para os cenários potenciais considerados nesta avaliação de risco, obteve-se, para o Cenário Potencial 2, incremento e quociente de riscos superiores aos limites estabelecidos para os mesmos, indicando que, caso seja instalado um poço de captação próximo ao poço de monitoramento PPTX-070, haverá incidência de risco carcinogênico e não carcinogênico à saúde humana.

O Cenário Potencial 1, entretanto, que considera a ingestão e absorção dérmica de água superficial do Rio Caí, apresentou valores de incremento e quociente de riscos iguais a $0,00 \mathrm{E}+00$, o qual indica que os compostos simulados não atingem esse Rio.

Avaliação de risco para as frações de hidrocarbonetos totais de petróleo (TPH)

A simulação de risco para as frações de hidrocarbonetos totais de petróleo (TPH) foi executada para as áreas da Oxiteno (OXI) e Petroflex (PTX), definidas como áreas potenciais de enfoque.

Em 2006, as amostras da PTX foram enviadas para o laboratório Analytical Solutions, conforme laudos apresentados na tabela 11.

Tabela 11: Concentrações dos Compostos de Interesse, em mg/L

\begin{tabular}{|c|c|c|}
\hline Composto & Alifático & Aromático \\
\hline Benzeno & -- & 0,026 PPTX 070A \\
\hline Etilbenzeno & -- & 0,070 PPTX 070A \\
\hline Xilenos (totais) & -- & $<0,005$ \\
\hline Tolueno & -- & $<0,005$ \\
\hline C6-C8 & $<0,005$ & $<0,005$ \\
\hline C8-C10 & 0,032 (PPTX 070) & 0,088 (PPTX 070) \\
\hline C10-C12 & 0,024 (PPTX 069) & 0,063 (PPTX 070) \\
\hline C12-C16 & 0,025 & 0,016 (PPTX 067) \\
\hline C16-C21 & $0,100 *$ & 0,023 \\
\hline C21-C32 & $*$ & 0,055 \\
\hline C8-C10 & 0,4 (POXI 029) & 0,4 POXI 028) \\
\hline \multicolumn{2}{|c|}{} \\
* corresponde à somatória das frações C16-21 e C21-C35
\end{tabular}


A Tabela 12 exibe os sumários dos quocientes de risco e incremento de risco, calculados para os compostos BTEX e TPH.

Tabela 12: Sumários dos incrementos e quocientes de riscos calculados - BTEX e TPH

\begin{tabular}{|c|c|c|c|c|c|c|}
\hline Cenário & Área & Receptores & Fonte & Rotas de Exposição & $\begin{array}{c}\text { Incremento } \\
\text { de risco }\end{array}$ & $\begin{array}{c}\text { Quociente } \\
\text { de risco }\end{array}$ \\
\hline $\begin{array}{c}\text { Potencial } \\
1\end{array}$ & Rio Caí & $\begin{array}{c}\text { Residentes (represen- } \\
\text { tados por uma criança } \\
\text { típica) }\end{array}$ & Água superficial & $\begin{array}{c}\text { Contato dérmico e inges- } \\
\text { tão. }\end{array}$ & $0,00 \mathrm{E}+00$ & $0,00 \mathrm{E}+00$ \\
\hline $\begin{array}{c}\text { Trabalhadores } \\
2\end{array}$ & Petroflex & Trabalhadores & Água subterrânea & $\begin{array}{c}\text { Contato dérmico, ingestão } \\
\text { e inalação de vapores e } \\
\text { gotículas. }\end{array}$ & $2,20 \mathrm{E}-05$ & $8,10 \mathrm{E}+00$ \\
\hline $\begin{array}{c}\text { Potencial } \\
3\end{array}$ & Oxiteno & Trabalhadores & Água subterrânea & $\begin{array}{c}\text { Contato dérmico, ingestão } \\
\text { e inalação de vapores e } \\
\text { gotículas. }\end{array}$ & - & $3,80 \mathrm{E}+00$ \\
\hline Real 1 & Petroflex & Trabalhadores & Água subterrânea & $\begin{array}{c}\text { Inalação de vapores em } \\
\text { ambientes abertos. }\end{array}$ & $3,70 \mathrm{E}-10$ & $2,30 \mathrm{E}-04$ \\
\hline Real 2 & Oxiteno & Trabalhadores & Água subterrânea & $\begin{array}{c}\text { Inalação de vapores em } \\
\text { ambientes abertos. }\end{array}$ & - & $3,90 \mathrm{E}-04$ \\
\hline Real 3 & Petroflex & Trabalhadores & Água subterrânea & $\begin{array}{c}\text { Inalação de vapores em } \\
\text { ambientes fechados. }\end{array}$ & $2,80 \mathrm{E}-08$ & $1,90 \mathrm{E}-02$ \\
\hline Real 4 & Oxiteno & Trabalhadores & Água subterrânea & $\begin{array}{c}\text { Inalação de vapores em } \\
\text { ambientes fechados. }\end{array}$ & - & $3,30 \mathrm{E}-02$ \\
\hline
\end{tabular}

Verifica-se que o quociente de risco (não carcinogênico) para o Cenário Potencial 3 apresentou um valor positivo que supera em 3,8 vezes o limite aceitável, ou seja, dose diária média no máximo igual à dose de referência. Para o Cenário Potencial 2, o valor do quociente encontra-se 8,1 vezes acima do limite aceitável.

As simulações de risco efetuadas somente para os compostos BTEX indicaram valores acima dos limites preconizados pelos órgãos ambientais somente em um cenário hipotético de utilização de água captada em área próxima ao poço PPTX 070 original. Os demais cenários apresentam riscos dentro dos limites aceitáveis. Os valores de concentração nesse poço são da ordem de dezenas de $\mathrm{mg} / \mathrm{L}$.

As simulações para TPH em forma fracionada foram executadas para duas campanhas de amostragem. As amostras da primeira campanha foram analisadas pela Innolab (referência, cidade, estado) apresentando valores positivos somente para os compostos de fração alifática $\mathrm{C} 8-\mathrm{C} 10$ e da aromática C8-C10. Porém, o limite de detecção do método foi considerado inadequado $(0,1$ $\mathrm{mg} / \mathrm{L}$ ), apesar do menor nível de filtragem inicial para risco ser de $0,23 \mathrm{mg} / \mathrm{L}$ para ingestão de água
(RISC $\left.4^{\circledR}, 2001\right)$.

No entanto, considerando-se as rotas hipotéticas do cenário potencial, o quociente de risco total foi calculado em 3,8 o que significa que as concentrações devem ser decrescidas em 3,8 vezes para que não se configure risco para o cenário definido.

Nesse mesmo cenário, ressalta-se que não foram detectados valores correspondentes à faixa C5-C6 e C6-C8, onde se encontram os compostos padronizados (BTEX), como pode ser visto na Tabela 11. Assim, caso a avaliação de risco fosse feita somente para os compostos BTEX, o valor seria igual a zero, contra um quociente de 3,8 quando se inclui toda a gama de hidrocarbonetos. Enquanto as simulações originais indicaram ausência de risco, ao se analisar todas as frações de hidrocarbonetos, de acordo com limites adequados, a redução necessária nas concentrações é maior.

Uma análise melhor pode ser feita na simulação relativa à área compreendida pelos poços denominados PPTX. Inicialmente, foi feita a avaliação com as máximas concentrações encontradas durante as campanhas desde 1999, ou seja, $17,7 \mathrm{mg} / \mathrm{L}$ de etilbenzeno, e $1,53 \mathrm{mg} / \mathrm{L}$ de xilenos totais. 
Os valores de incremento de risco (carcinogênico, advindo do benzeno) e quociente de risco acima dos limites aceitáveis também foram identificados no Cenário Potencial 2, em valores de $9,6 \times 10^{-4}$ e $3,2 \times 10^{1}$, respectivamente. Isso significa que a concentração do benzeno deve ser reduzida em duas ordens de grandeza para atingir o limite aceitável de $10^{-5}$ e os demais compostos em 32 vezes.

As amostras da área PPTX, analisadas para toda a gama de hidrocarbonetos, apresentaram concentrações de $0,026 \mathrm{mg} / \mathrm{L}$ de benzeno (PPTX 070A) e 0,070 mg/L de etilbenzeno (PPTX 070A), além de diversas concentrações nas faixas de carbono equivalente, entre alifáticos e aromáticos, porém, sempre com valores não superiores a 0,088 mg/L (C8-C10 aromático no poço PPTX 070A).

Os valores de incremento de risco (carcinogênico, advindo do benzeno) e quociente de risco acima dos limites aceitáveis também foram identificados no Cenário Potencial 2, em valores de $2,2 \times 10^{-5}$ e $8,1 \times 10^{0}$, respectivamente. $\mathrm{O}$ benzeno encontra-se, portanto, quase no limite aceitável de risco, devendo ser reduzido pouco mais de 2 vezes e os demais compostos em cerca de 8 vezes (considerando-se todos os compostos e não cada um individualmente).

Embora o risco calculado esteja menor que na simulação inicial, deve ser ressaltada a ordem de grandeza das concentrações. Na primeira simulação as concentrações são da ordem de unidade e dezena de $\mathrm{mg} / \mathrm{L}$, sendo que na segunda simulação as concentrações são da ordem de $10^{-2}$ $\mathrm{mg} / \mathrm{L}$.

Novamente constata-se que se na campanha efetuada no poço original PPTX 070 fossem analisadas todas as faixas de hidrocarbonetos, o risco calculado seria bem maior.

Para ilustrar diferença entre as abordagens, a tabela abaixo exibe os riscos calculados com as concentrações da última campanha, considerandose apenas BTEX e considerado-se BTEX e TPH.

Tabela 13: Concentrações na área da Petroflex

\begin{tabular}{|c|c|c|c|c|c|c|}
\hline \multicolumn{7}{|c|}{ Com as concentrações atuais da área da Petroflex (excluindo o TPH) } \\
\hline Cenário & Area & Receptores & Fonte & Rotas de Exposição & $\begin{array}{c}\text { Incremento } \\
\text { de Risco }\end{array}$ & $\begin{array}{c}\text { Quociente de } \\
\text { Risco }\end{array}$ \\
\hline \multirow[t]{2}{*}{ Potencial 1} & \multirow[t]{2}{*}{ Rio Caí } & $\begin{array}{l}\text { Residentes } \\
\text { (representados por } \\
\text { uma criança típica) }\end{array}$ & \multirow[t]{2}{*}{$\begin{array}{c}\text { Água } \\
\text { superficial }\end{array}$} & \multirow[t]{2}{*}{$\begin{array}{l}\text { Contato dérmico e } \\
\text { ingestão. }\end{array}$} & $0,00 \mathrm{E}+00$ & $0,00 \mathrm{E}+00$ \\
\hline & & Trabalhadores & & & $0,00 \mathrm{E}+00$ & $0,00 \mathrm{E}+00$ \\
\hline Potencial 2 & Petroflex & Trabalhadores & $\begin{array}{c}\text { Água } \\
\text { subterrânea }\end{array}$ & $\begin{array}{l}\text { Contato dérmico, ingestão } \\
\text { e inalação de vapores e } \\
\text { gotículas. }\end{array}$ & $2,20 \mathrm{E}-05$ & $3,80 \mathrm{E}-01$ \\
\hline Real 1 & Petroflex & Trabalhadores & \begin{tabular}{|c|} 
Água \\
subterrânea
\end{tabular} & $\begin{array}{l}\text { Inalação de vapores em } \\
\text { ambientes abertos }\end{array}$ & $3,70 \mathrm{E}-10$ & $5,50 \mathrm{E}-06$ \\
\hline Real 3 & Petroflex & Trabalhadores & $\begin{array}{c}\text { Água } \\
\text { subterrânea }\end{array}$ & $\begin{array}{c}\text { Inalação de vapores em } \\
\text { ambientes fechados }\end{array}$ & $2,80 \mathrm{E}-08$ & $4,10 \mathrm{E}-04$ \\
\hline \multicolumn{7}{|c|}{ Com as concentrações atuais da área da Petroflex (incluindo o TPH) } \\
\hline Cenário & Area & Receptores & Fonte & Rotas de Exposição & $\begin{array}{c}\text { Incremento } \\
\text { de Risco }\end{array}$ & $\begin{array}{c}\text { Quociente de } \\
\text { Risco }\end{array}$ \\
\hline \multirow[t]{2}{*}{ Potencial 1} & \multirow[t]{2}{*}{ Rio Caí } & $\begin{array}{c}\text { Residentes } \\
\text { (representados por } \\
\text { uma criança típica) }\end{array}$ & \multirow[t]{2}{*}{$\begin{array}{c}\text { Água } \\
\text { superficial }\end{array}$} & \multirow[t]{2}{*}{$\begin{array}{l}\text { Contato dérmico e } \\
\text { ingestão. }\end{array}$} & $0,00 \mathrm{E}+00$ & $0,00 \mathrm{E}+00$ \\
\hline & & Trabalhadores & & & $0,00 \mathrm{E}+00$ & $0,00 \mathrm{E}+00$ \\
\hline Potencial 2 & Petroflex & Trabalhadores & $\begin{array}{c}\text { Água } \\
\text { subterrânea }\end{array}$ & $\begin{array}{l}\text { Contato dérmico, ingestão } \\
\text { e inalação de vapores e } \\
\text { gotículas. }\end{array}$ & $2,20 \mathrm{E}-05$ & $8,10 \mathrm{E}+00$ \\
\hline Real 1 & Petroflex & Trabalhadores & \begin{tabular}{|c|} 
Água \\
subterrânea
\end{tabular} & $\begin{array}{l}\text { Inalação de vapores em } \\
\text { ambientes abertos }\end{array}$ & $3,70 \mathrm{E}-10$ & $2,30 \mathrm{E}-04$ \\
\hline Real 3 & Petroflex & Trabalhadores & $\begin{array}{c}\text { Água } \\
\text { subterrânea }\end{array}$ & $\begin{array}{c}\text { Inalação de vapores em } \\
\text { ambientes fechados }\end{array}$ & $2,80 \mathrm{E}-08$ & 1,90E-02 \\
\hline
\end{tabular}

Verifica-se na Tabela 13, que, para os cenários Potencial 2, e Real 1 e 3, ocorre um incremento de duas ordens de grandeza nos quocientes de risco, decorrentes da quantificação dos efeitos adversos de todas as frações de hidrocarbonetos de petróleo, em comparação à BTEX somente. 


\section{CONCLUSÕES}

A quantificação do risco toxicológico associado a toda a gama de hidrocarbonetos de petróleo apresentou valores mais restritivos do que as avaliações executada para a mesma amostra, quando considerou-se somente os compostos padronizados benzeno, tolueno etilbenzeno, e xilenos (BTEX), As variações foram de até duas ordens de grandeza no quociente de risco.

Análise matemática da incerteza na utilização das duas abordagens, ou seja, avaliação de risco para compostos padronizados, que possuem doses de referência e avaliação de risco que considera estes compostos e agrega as doses de referência de compostos remanescentes, não pôde ser realizada, em função de algumas amostras apresentarem concentração nula ou abaixo do limite de detecção do método para compostos padronizados,. $\mathrm{Na}$ amostra com presença de compostos padronizados e compostos remanescentes, a imprecisão na quantificação do risco foi de grande magnitude.

A definição do risco e conseqüentemente cálculo inverso de resposta ou definição de metas de remediação ou ainda concentrações alvo, é fundamental na tomada de decisão de remediação de áreas contaminadas. As estratégias de remediação levam em consideração o particionamento ambiental dos compostos. No caso das frações de hidrocarbonetos de petróleo, ocorrem variações de até sete ordens de grandeza nas solubilidades das diversas frações enquanto que pressões de vapor variam em até duas ordens de grandeza.

A desconsideração de frações que apresentam características específicas de particionamento pode levar à uma subestimativa no dimensionamento dos sistemas de remediação, pois seriam somente consideradas, nesse caso, as características dos compostos aromáticos padronizados BTEX.

As avaliações de risco em locais impactados por hidrocarbonetos de petróleo devem ser efetuadas para os compostos carcinogênicos presentes e para as frações alifáticas e aromáticas e não somente para compostos padronizados, BTEX ou HPA's.

A definição cientificamente adequada de metas de remediação e adoção de um programa de gestão específico e objetivo deve considerar toda a gama de hidrocarbonetos. Uma vez sendo necessária a redução de massa das frações para atingir metas de remediação, é imperativo levar em consideração as características de particionamento dos compostos, pois há variações de até duas ordens de grandeza na pressão de vapor das frações de hidrocarbonetos enquanto que a solubilidade apresenta até sete ordens de grandeza. Assim, as tecnologias de remediação podem ser erroneamente empregadas se não considerada toda a gama de hidrocarbonetos de petróleo.

\section{REFERÊNCIAS BIBLIOGRÁFICAS}

AMERICAN PETROLEUM INSTITUTE (1985) Oil Spill Cleanup: Options for Minimizing Adverse Ecological Impacts. Health and Environmental Science Department, N.435.

AMERICAN PETROLEUM INSTITUTE (1999) Fate of Spilled Oil in Marine Waters: Where does it go? What does it do? How do Dispersants Affect it? In: API Publication Number 4691, USA.

AMERICAN SOCIETY FOR TESTING AND MATERIALS (1995) Standard Guide for RiskBased Corrective Action Applied at Petroleum Release Sites. E 1739-95e $\mathrm{e}^{1}$, ASTM. 51 p. AMERICAN SOCIETY FOR TESTING AND MATERIALS (1995) Standard Guide for General Planning of Waste Sampling, ASTM. D4687, 208 p. AMERICAN SOCIETY FOR TESTING AND MATERIALS (2000) Standard Guide for RiskBased Corrective Action. E 2081 - 00, ASTM. 32 p. COMPANHIA DE TECNOLOGIA DE SANEAMENTO AMBIENTAL (1990)
Compilação de Padrões Ambientais. Diretoria de Normas e Padrões Ambientais. CETESB, 04 p.

COMPANHIA DE TECNOLOGIA DE SANEAMENTO AMBIENTAL (2001) Ações Corretivas Baseadas em Risco (ACBR) Aplicadas a Áreas Contaminadas com Hidrocarbonetos de Petróleo e Outros Combustíveis Líquidos Relatório Final. CETESB, 80 p.

COMPANHIA DE TECNOLOGIA DE SANEAMENTO AMBIENTAL GTZ (Deutsche Gesellschaft für Technische Zusammenarbeit) (2004) Manual de Gerenciamento de Áreas Contaminadas. Cap. 9000 Cooperação Técnica Brasil-Alemanha, CETESB , $66 \mathrm{p}$.

DOUGLAS, G. S.; PRINCE, E. L.; BUTLER, E. L.; STEINHAUER, W. G. The Use of Internal Chemical Indicators in Petroleum and Refined Products to Evaluate the Extent of Biodegradation. In: HINCHEE, R. E., ALLEMAN, B. C., HOEPPEL, R. E.; MILLER R. N.. Hydrocarbon Bioremediation. Tokyo: Lewis Publishers, 1994, p. 477 
FROTA NACIONAL DE PETROLEIROS Plano de Emergência para Derrames de Hidrocarbonetos. PETROBRAS-FRONAPE, Inspetoria Geral, Rio de Janeiro, 2002, 112 p.

HUESMANN, M.H.; MOORE, K.O. The Effects of Soil Type, Crude Oil Type and Loading, Oxygen, and Commercial Bacteria on Crude Oil Bioremediation Kinetics as Measured by Soil Respirometry. In: HINCHEE, R.E.; ALLEMAN, B.C.; HOEPPEL, R.E.; MILLER, R.N. Hydrocarbon Bioremediation. Ed. Tokyo: Lewis Publishers, 1994. p.477.

NORRIS, R.D.; DOWD, K.; MAUDLIN, C. The Use of Multiple Oxygen Sources and Nutrient Delivery Systems to Effect in situ Bioremediation of Saturated and Unsatureted Soils. In: HINCHEE, R.E.; ALLEMAN, B.C.; HOEPPEL, R.E.; MILLER, R.N. Hydrocarbon Bioremediation. Ed. Tokyo: Lewis Publishers, 1994. p.477.

PRINCE, R.C.; CLARK, J.R.;BUTLER, L.E.L. Bioremediation of the Exxon Valdez Oil Spill: Monitoring, Safety and Efficacy. In: HINCHEE, R.E.; ALLEMAN, B.C.; HOEPPEL, R.E.; MILLER, R.N. Hydrocarbon Bioremediation. Ed. Tokyo: Lewis Publishers, 1994. p.477.

REIS, M. M. Avaliação de Risco de Benzeno em Volta Redonda: As Incertezas na Avaliação da Exposição. 2004. Dissertação (Mestrado). Escola Nacional de Saúde Pública, Rio de Janeiro, 74 p.
RISC $\AA$. Risk-Integrated Software for CleanUps. User's Manual. BP Oil International. Sunbury: 2001.

TEXAS NATURAL RESOURCE CONSERVATION COMMISSION (2000) Development of Human Health PCLs (Protective Contaminant Levels) for Total Petroleum Hydrocarbon Mixtures. TNRCC, 21 p.

TROY, M.A.; JERGER, D.E. Matrix Effects on the Analytical Techniques Used to Monitor the Full-scale Biological Land Treatment of Diesel Fuel-contaminated Soils. In: HINCHEE, R.E.; ALLEMAN, B.C.; HOEPPEL, R.E.; MILLER, R.N. Hydrocarbon Bioremediation. Ed. Tokyo: Lewis Publishers, 1994. p.477.

VORHEES, D. J.; WEISNAM, W.H.; GUSTAFSON, J.B. Total Petroleum Hydrocarbon Criteria Working Group Human Health RiskBased Evaluation of Petroleum Release Sites: Implementing the Working Group Approach. v.5, 60p., 1999.

U.S. ENVIRONMENTAL PROTECTION AGENCY (1986b) Guidelines for the Health Risk Assessment of Chemical Mixtures. Federal Register 52:34014 - 34025. Washington, EPA, 23 p.

U.S. ENVIRONMENTAL PROTECTION AGENCY (1992) Guideline for Exposure Assessment: Notice. Federal Register 57:2288822938. Washington, EPA, 54 p. 
